\title{
Aporte de serapilheira e teor de carbono orgânico em um fragmento florestal urbano
}

Os fragmentos florestais urbanos produzem inúmeros serviços ecossistêmicos que contribuem diretamente para a melhoria da qualidade ambiental das cidades, como a produção de oxigênio atmosférico a fixação de carbono, a ciclagem de nutrientes e a conservação da natureza. A importância destes serviços não deve se atribuída exclusivamente ao componente arbóreo ou a seu dossel, mas a todo o conjunto de componentes de uma floresta, incluindo a serapilheira, responsáve pela sustentabilidade de todo o ecossistema. Os objetivos deste trabalho foi avaliar o aporte e a quantidade e teor de carbono em diferentes classes de serapilheira depositada em um fragmento florestal localizado em Curitiba, Paraná. Para isso, 30 parcelas foram distribuídas ao longo de uma trilha no interior deste fragmento para coletar a serapilheira, entre os meses de outono e inverno de 2019. A serapilheira coletada foi separada e classificada em: folhas; galhos e cascas; raízes; estruturas reprodutivas e miscelânea. O peso úmido e seco deste material foi determinado e por meio de um analisador de carbono por combustão o percentual de carbono foi definido. Os resultados indicam um aporte de serapilheira no valor de 11,61 Mg/ha, com predomínio da classe galhos e cascas (6,30 Mg/ha). A quantidade média de carbono neste aporte corresponde a 5,08 Mg/ha e o teor médio de carbono foi significativamente maior na classe miscelânea (44,46\%) em relação às outras classes de serapilheira. Conclui-se que o fragmento florestal avaliado, apesar de isolado e antropizado, apresentou tanto aporte de serapilheira quanto quantidade e teor de carbono semelhantes aos encontrados em florestas com menos intervenções urbanas, demonstrando ser a serapilheira um parâmetro eficiente para se avaliar o estado de conservação destes ambientes.

Palavras-chave: Fitomassa florestal; Floresta urbana; Conservação.

\section{Litter increase and organic carbon content in urban forest fragment}

Urban forest fragments produce numerous ecosystem services that directly contribute to improving the environmental quality of cities, such as the production of atmospheric oxygen, carbon fixation, nutrient cycling and nature conservation. The importance of these services should not be attributed exclusively to the tree component or its canopy, but to the entire set of components of a forest, including litter, which is responsible for the sustainability of the entire ecosystem. The objective of this research was to evaluate the contribution and the quantity and carbon content in different classes of litter deposited in a forest fragment located in Curitiba, Paraná. For this, 30 plots were distributed along a trail inside this fragment to collect the litter, between the autumn and winter months of 2019. The collected litter was separated and classified into: leaves; branches and barks; roots; reproductive structures and miscellaneous. The wet and dry weight of this material was determined and through a combustion carbon analyzer the carbon percentage was defined. The results indicate an amount of litter of $11.61 \mathrm{Mg} / \mathrm{ha}$, with a predominance of branches and barks $(6.30 \mathrm{Mg} / \mathrm{ha}$ ). The average amount of carbon in this contribution corresponds to $5.08 \mathrm{Mg} / \mathrm{ha}$ and the average carbon content was significantly higher in the miscellaneous class (44.46\%) in relation to the other litter classes. It is concluded that the evaluated forest fragment, despite being isolated and anthropized, presented an amount of litter and the amount and carbon content similar to those found in forests with less urban interventions, demonstrating that litter is an efficient parameter to assess the conservation status these environments.

Keywords: Forest phytomass; Urban forest; Conservation

Topic: Conservação da Biodiversidade

Reviewed anonymously in the process of blind peer.
Received: 04/09/2020

Approved: 09/11/2020
Daniela Biondi Batista (iD)

Universidade Federal do Paraná, Brasil

http://lattes.cnpq.br/0187857348523672

http://orcid.org/0000-0003-0532-7363

dbiondi@ufpr.br

Fernando Vicente Dácol (iD)

Universidade Federal do Paraná, Brasil

http://lattes.cnpq.br/2498327140132893

http://orcid.org/0000-0002-9135-1759

fernando.dacol@gmail.com

Ana Paula Dalla Corte

Universidade Federal do Paraná, Brasil

http://lattes.cnpq.br/9528175326712747

http://orcid.org/0000-0001-8529-5554

anapaulacorte@gmail.com

\section{Angeline Martine (iD) \\ Universidade Federal de Viçosa, Brasil \\ http://lattes.cnpq.br/1793083628826054 \\ http://orcid.org/0000-0002-4500-1221 \\ martini.angeline@gmail.com \\ Allan Rodrigo Nunho Reis (iD \\ Universidade Federal do Paraná, Brasil \\ http://lattes.cnpq.br/9300850097951293 \\ http://orcid.org/0000-0001-5878-4707 \\ allan.nunho@gmail.com}

\section{Referencing this:}

BATISTA, D. B.; DÁCOL, F. V.; CORTE, A. P. D.; MARTINE, A.; REIS, A. R. N.. Aporte de serapilheira e teor de carbono orgânico em um fragmento florestal urbano. Nature and Conservation, v.13, n.4, p.2230, 2020. DOI: http://doi.org/10.6008/CBPC2318-2881.2020.004.0003 


\section{INTRODUÇÃO}

Os fragmentos florestais possuem uma expressiva relevância no meio urbano, por serem responsáveis pelos serviços ambientais e ecossistêmicos que regulam o ambiente e fornecem condições para o bem-estar da população nas cidades. As cidades representam um elo importante entre pessoas e natureza, de modo que, embora gerem intensos impactos ambientais, promovem serviços ecossistêmicos fundamentais para os processos ecológicos e sociais (ELMQVIST et al., 2015). Projeções globais apontam que a rápida expansão das áreas urbanas promove desafios e oportunidades para projetar cidades mais habitáveis, saudáveis e resilientes, como uma Solução Baseada na Natureza (SBN) para se adaptarem aos efeitos nocivos ocasionados pela mudança do clima (ELMQVIST et al., 2015; MEXIA et al., 2018), considerando as atividades antrópicas na emissão de Gases de Efeito Estufa (GEEs).

Um dos serviços ecossistêmicos mais importantes proporcionados pelos fragmentos florestais urbanos é a fixação do dióxido de carbono $\left(\mathrm{CO}_{2}\right)$ presente na atmosfera, na forma de armazenamento de carbono na fitomassa à medida que a vegetação se desenvolve (FEARNSIDE et al., 2013). Amaral et al. (2017) consideram a fixação de carbono pela fitomassa um dos principais serviços ecossistêmicos que mais contribuem para a absorção biológica de carbono no planeta.

Sabe-se que as florestas urbanas têm um papel importante na fixação de do dióxido de carbono $\left(\mathrm{CO}_{2}\right)$ emitido pelas atividades urbanas, podendo assim, contribuir para mitigar os efeitos nocivos da mudança do clima (NOWAK et al., 2002). Além disso, a serapilheira, que corresponde à fitomassa morta depositada sobre o solo florestal, é um indicador da capacidade do ambiente em fixar e armazenar carbono, além de contribuir para a manutenção dos processos ecológicos e a regulação das condições ambientais.

Freschet et al. (2013) constaram que, em média, a quantidade anual de folhas na serapilheira produzida por uma árvore representa cerca de $41 \%$ de sua fitomassa total, enquanto galhos finos e raízes finas correspondem com 11 e 48\%, respectivamente. Por isso, a dinâmica da matéria orgânica em ecossistemas florestais pode ser relativamente bem compreendida apenas por estimativas de decomposição da serapilheira (FRESCHET et al., 2013).

Caldeira et al. (2008) e Godinho et al. (2013) consideram que as pesquisas que abordam a produção e acúmulo de serapilheira podem subsidiar a compreensão sobre a ciclagem dos nutrientes no ecossistema, permitindo o planejamento do manejo, inclusive em áreas antropizadas.

Os fragmentos florestais urbanos são pouco pesquisados no âmbito da conservação, possivelmente devido ao seu objetivo não ser o fornecimento de madeira, mas a sua contribuição no fornecimento de serviços ecossistêmicos, como a produção de oxigênio atmosférico, a ciclagem de nutrientes, a fixação de carbono e a conservação de solos e da água. Saber mais sobre o estado de conservação dos fragmentos florestais urbanos por meio de comparação com outras áreas florestais menos alteradas, pode dar início a duas medidas efetivas: (a) respeitar e conservar pela sua importância comprovada e (b) recuperar a área para alcançar os benefícios esperados.

Para reforçar a importância da especificidade do manejo dessas florestas, Elias et al. (2018) afirmam 
que os fragmentos florestais urbanos não podem ser manejados do mesmo modo que uma área contínua, porque além de serem fragmentados e impactados, as ações de manejo e restauração precisam ser imperativas. Além disso, Munhoz et al. (2017) recomendam esforços para compreender dinâmica dos ecossistemas urbanos e seus serviços para embasar as estratégias de planejamento urbano com critérios de sustentabilidade.

Desse modo, visando ressaltar a importância dos fragmentos florestais no ambiente urbano e o pouco conhecimento sobre o material vegetal depositado nestes ambientes, esta pesquisa teve como objetivo avaliar o aporte e a quantidade e o teor de carbono em diferentes classes de serapilheira depositada em um fragmento florestal localizado em Curitiba, Paraná. O trabalho foi realizado de forma expedita, caracterizando-se como uma pesquisa exploratória para subsidiar futuros estudos de caráter sazonal com parcelas permanentes.

\section{MATERIAIS E MÉTODOS}

\section{Área de estudo}

A pesquisa foi realizada em um fragmento florestal urbano localizado no município de Curitiba, capital do Estado do Paraná, Sul do Brasil, entre as coordenadas 2526'50"S e 2527'33"S e 4914'16"W e 4914'33"W (Figura 1), com altitude do terreno variando entre 890 e 915 m (MACHADO et al., 2008).

O fragmento florestal, conhecido por Capão do Tigre, está localizado no campus III - Jardim Botânico, da Universidade Federal do Paraná (UFPR). Possui uma área total de 15 ha, sendo 12,96 ha correspondentes à Floresta Ombrófila Mista (FOM) Montana, com a predominância da espécie Araucaria angustifolia (Bertol.) Kuntze (araucária) e o restante, 2,28 ha, é dividido entre capoeiras e capoeirões, com predominância de taquaras (RONDON NETO et al., 2002).

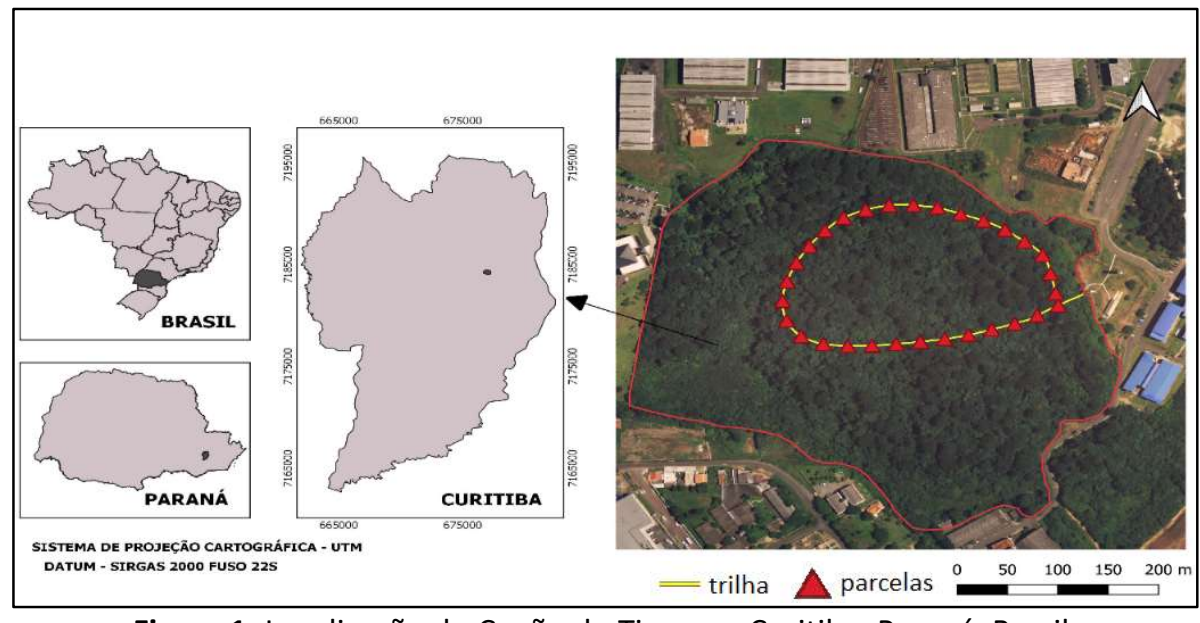

Figura 1: Localização do Capão do Tigre em Curitiba, Paraná, Brasil.

Segundo a classificação de Köppen-Geiger, a zona climática da região de Curitiba é do tipo Cfb, com características de clima subtropical úmido (IPPUC, 2015). A temperatura média anual da região é de 17,51 ${ }^{\circ} \mathrm{C}$, chegando até $33,87{ }^{\circ} \mathrm{C}$ no verão e $-2,35{ }^{\circ} \mathrm{C}$ no inverno; a pluviosidade média é de $1587,52 \mathrm{~mm} /$ ano e a umidade relativa média anual é de 81,94\% (WREGE et al., 2015). 
O Capão do Tigre é caracterizado como uma floresta secundária com uma expressiva quantidade de espécies pioneiras e diâmetros de pequenas dimensões, porém com características originais modificadas em função da antropização do entorno (MACHADO et al., 2008). No capão existem cerca de 349 indivíduos de $A$. angustifolia, alguns com aproximadamente 100 anos de idade, representando em média 26,85 árvores por ha (MACHADO et al., 2008). Os solos da região são classificados em hidromórficos, nas regiões próximas aos canais de drenagem; e cambissolos e podzólicos nas regiões drenadas, com relevo suave ondulado (RONDON NETO et al., 2002).

\section{Procedimentos metodológicos}

Por se tratar de uma pesquisa exploratória com avaliação expedita foram estabelecidas 30 parcelas. A coleta das 30 amostras ocorreu ao longo dos meses de abril, maio, junho e julho de 2019, representando o outono e parte do inverno. As amostras coletadas foram distribuídas ao longo de uma trilha com $750 \mathrm{~m}$ de extensão, no interior do fragmento (Figura 1). A serapilheira foi coletada em parcelas com dimensões de 0,25 x 0,25 m (0,0625 $\left.\mathrm{m}^{2}\right)$, instalados a cada $20 \mathrm{~m}$ de distância, adentrando $5 \mathrm{~m}$ da borda da trilha (para diminuir a influência da trilha), alternando-se os lados para cada parcela. Não fizeram parte do estudo os $75 \mathrm{~m}$ iniciais e finais da trilha, por estarem próximos a borda do fragmento.

Logo após a coleta, a serapilheira foi separada e classificada nas seguintes classes: folhas; galhos e cascas; raízes; estruturas reprodutivas e miscelânea, correspondente ao material vegetal de difícil distinção, conforme recomendado por Dickow et al. (2012). Depois de classificada, a serapilheira foi pesada para determinar o peso úmido e então colocada em sacos de papel para a secagem em estufa de circulação forçada, programada para manter a temperatura constante de $75^{\circ} \mathrm{C}$ por $48 \mathrm{~h}$, pesando-se novamente para obter o peso seco. Para a pesagem foi utilizada uma balança mecânica com precisão de décimos de grama.

Para análise do carbono, as amostras de cada classe de serapilheira foram moídas em um macro moinho de facas STAR FT 60 da marca Fortinox, pesadas com aproximadamente $0,1 \mathrm{~g}$, transferidas para cadinhos de porcelana e colocadas no analisador de carbono por combustão total LECO C - 144, o qual registra os resultados em formato digital. O método utilizado consiste na combustão total da amostra e através de um sensor infravermelho é determinada a quantidade de $\mathrm{CO}_{2}$ que é liberada pela combustão e relacionada com o percentual de carbono contido na amostra.

Os dados foram inseridos em planilhas do programa Microsoft Office Excel e analisados estatisticamente por meio do software Assistat versão 7.7. Para a análise estatística, foi utilizado o teste SNK (Student-Newman-Keuls) para comparar as médias dos valores de peso seco $(\mathrm{kg} / \mathrm{ha})$, peso úmido $(\mathrm{kg} / \mathrm{ha})$ e percentual de carbono (\%) entre as cinco classes de serapilheira, com 30 repetições cada.

\section{RESULTADOS E DISCUSSÃO}

Na tabela 1, é apresentado o aporte total de serapilheira do fragmento florestal, assim como as contribuições médias referentes às suas classes, em porcentagem. A quantidade total de serapilheira coletada correspondeu a $11,61 \mathrm{Mg} / \mathrm{ha}$, com predomínio da classe galhos e cascas, constituindo $6,30 \mathrm{Mg} / \mathrm{ha}$. 
Tabela 1: Análise da quantidade de serapilheira do Capão do Tigre em diferentes classes

\begin{tabular}{lll}
\hline Classes de Serapilheira & $\mathbf{M g} / \mathbf{h a}$ & $\%$ \\
\hline Folhas & $3,65 \mathbf{b}$ & 31,42 \\
Galhos e Cascas & $6,30 \mathbf{~ a ~}$ & 54,25 \\
Raízes & $0,25 \mathbf{c}$ & 2,14 \\
Estruturas Reprodutivas & $0,43 \mathbf{c}$ & 3,74 \\
Miscelânea & $0,98 \mathbf{c}$ & 8,45 \\
\hline Total & 11,61 & 100,00 \\
\hline
\end{tabular}

Nota: Letras diferentes diferem estatisticamente pelo teste SNK na linha vertical.

Embora a avaliação realizada tenha sido de forma expedita, os resultados obtidos podem ser comparados com outras pesquisas conduzidas em fragmentos florestais, podendo-se inferir sobre a qualidade ambiental. Destaca-se que a quantidade, a dinâmica e as frações constituintes da serapilheira variam em função diversos fatores, tanto bióticos quanto abióticos. Exemplos de fatores que influenciam na serapilheira são: tipologia florestal; condições edafoclimáticas da região; sítio; sub-bosque; proporção de copa; distúrbios naturais, como fogo e ataque de insetos; ou artificiais, como remoção de serapilheira entre as espécies; além da fisiologia das espécies (GODINHO et al., 2013; BERG, 2014; GODINHO et al., 2014; BRADFORD et al., 2016). Figueiredo Filho et al. (2003) acrescentam que um determinado fator pode prevalecer sobre os demais, dependendo das características de cada ambiente.

Oliveira (2010) afirma que nas florestas onde é maior a escassez de nutrientes, ocorre maior acúmulo de serapilheira, reduzindo a velocidade com que estes são ciclados. Vidal et al. (2007) consideram ainda importante relacionar a quantidade de serapilheira com as perturbações antropogênicas no seu entorno, sendo um aspecto comum aos fragmentos de floresta urbana.

Considerando fragmentos de FOM, Floss et al. (1999) compararam o aporte de serapilheira de duas modalidades de FOM em Caçador, SC, a primeira com maior frequência de $A$. angustifolia no estrato superior e outra com maior diversidade de espécies e predomínio de outras espécies no estrato superior, obtendo a quantidade de 9,7 e 7,5 Mg/ha, respectivamente. Já Watzlawick et al. (2002) compararam um fragmento de floresta em General Carneiro, PR, em diferentes estágios sucessionais, obtendo as seguintes quantidades de serapilheira: $7,9 \mathrm{Mg} /$ ha para o estágio inicial, $8,6 \mathrm{Mg} /$ ha para o estágio médio e $7,6 \mathrm{Mg} / \mathrm{ha}$ para o estágio avançado. Na mesma região, Watzlawick et al. (2012) obtiveram 8,01 Mg/ha. Também em uma de floresta em Irati, PR, Oliveira (2010) encontrou $12,61 \mathrm{Mg} / \mathrm{ha}$.

De modo geral, o aporte de serapilheira encontrado para o fragmento avaliado é comparável a pesquisas realizadas em outros fragmentos de FOM, independente da metodologia utilizada e da época de coleta. Para reforçar os valores observados, O'Connell et al. (1997) estabeleceram um padrão da quantidade de serapilheira para as florestas tropicais naturais em determinados locais da América do Sul, que pode variar de 3,1 a $16,5 \mathrm{Mg} / \mathrm{ha}$.

Com isso, ao se considerar apenas o aporte de serapilheira como parâmetro, verifica-se que o fragmento correspondente ao Capão do Tigre apresenta condições relativamente satisfatórias, quando comparado com fragmentos florestais sem influência urbana. Isto indica que o fragmento florestal, apesar de isolado e antropizado, consegue acumular uma quantidade de serapilheira razoável que pode fornecer suporte e melhoria aos fatores abióticos (solo, água e clima) e bióticos (fauna e flora) existentes no local. Este 
resultado se torna anda mais expressivo ao considerar o período de realização das coletas, visto que estudos anteriores em fragmentos de floresta com araucária, indicaram que o outono foi a estação com menor produção de serapilheira, decorrente da menor atividade metabólica das plantas (SANQUETTA et al., 2016). Assim, em futuras pesquisas de caráter sazonal com parcelas permanentes, será possível determinar a intensidade desse aporte.

Para Scoriza et al. (2017), a serapilheira é um indicador ambiental que expressa bem as características bióticas e abióticas dos fragmentos florestais. Além disso, devido a sensibilidade em responder às alterações do ambiente, baixo custo e praticidade, a análise da serapilheira constitui-se um instrumento para avaliação do estado de conservação de fragmentos, permitindo subsidiar tomadas de decisões relativas ao planejamento e a recuperação florestal (MACHADO et al., 2008; LLAUSÀS et al., 2012; SCORIZA et al., 2017).

Em relação à quantidade predominante da classe galhos e cascas, com $6,30 \mathrm{Mg} / \mathrm{ha}$, ou $54,25 \%$ do aporte de serapilheira, a tabela 1 indicou que esta é significativamente distinta das demais classes. A predominância desta classe pode estar associada ao maior período de coleta durante o outono (entre abril e julho), ao grau de maturidade ou estágio sucessional e ao tipo de floresta. Neste caso, geralmente as árvores maduras possibilitam maior desrama natural pela competição de luz e espaço entre os indivíduos arbóreos e, a maturidade de algumas espécies pode ser responsável pela descamação do tronco. Este fato pode indicar que este fragmento florestal urbano se encontra em estágio sucessional maduro.

A predominância das classes de serapilheira pode variar, mas em geral a classe folhas é que contribui com o maior aporte de fitomassa ao solo florestal, independentemente da fase sucessional em que a floresta se encontra, conforme sugerido por Dickow et al. (2012). Figueiredo Filho et al. (2003) afirmam que a composição de serapilheira em uma floresta geralmente é de 60 a $80 \%$ de folhas, 1 a $15 \%$ de ramos e 1 a 15\% de casca. Wisniewski et. al. (1997) encontraram em um fragmento de FOM, 57\% do total de serapilheira coletada correspondendo a folhas, $30 \%$ a galhos e 13\% à miscelânea. A quantidade média de carbono no aporte de serapilheira foi de 5,08 t/ha, conforme apresentado na tabela 2 .

Tabela 2: Teor e quantidade de carbono em serapilheira do Capão do Tigre.

\begin{tabular}{|c|c|c|c|c|}
\hline \multirow[t]{2}{*}{ Classes de Serapilheira } & \multicolumn{2}{|c|}{ Teor de Carbono } & \multicolumn{2}{|l|}{ Carbono } \\
\hline & Média (\%) & Desvio Padrão (\%) & Média (t/ha) & Desvio Padrão (t/ha) \\
\hline Folhas & $43,73 \quad c$ & 0,23 & $1,59 \mathbf{b}$ & 1,46 \\
\hline Galhos e Casca & 43,80 bc & 0,24 & $2,76 a$ & 1,67 \\
\hline Raiz & 43,99 b & 0,17 & $0,10 \mathrm{c}$ & 0,19 \\
\hline Est. Reprodutiva & 43,93 bc & 0,29 & $0,19 \mathrm{c}$ & 0,17 \\
\hline Miscelânea & 44,46 a & 0,47 & $0,44 \mathrm{c}$ & 0,33 \\
\hline Total & & & 5,08 & 2,09 \\
\hline
\end{tabular}

Nota: Letras diferentes diferem estatisticamente pelo teste SNK na coluna.

Considerando o mesmo tipo de floresta, o resultado de Oliveira (2010) em Irati, PR, foi semelhante, com 5,33 t/ha; em General Carneiro, PR, Watzlawick et al. (2012) encontraram 3,06 t/ha e, em São João do Triunfo, PR, Maas (2015) obteve 3,26 t/ha. Ressalta-se que estes valores são provenientes de florestas que não estão sob influência e pressão do ambiente urbano. Isto reforça a constatação de que o fragmento de floresta urbana avaliado desempenha satisfatoriamente sua função de estocar carbono na sua porção de serapilheira. 
Os resultados obtidos sugerem que na gestão das florestas urbanas não seja preconizada apenas a importância das árvores e seu dossel, mas também todo o conjunto de componentes de uma floresta, incluindo a serapilheira que faz parte do piso ou da superfície, responsável pela sustentabilidade do ecossistema por meio da ciclagem de nutrientes.

O potencial das florestas em armazenar carbono no solo e na serapilheira faz com que as medidas de conservação sejam relevantes tanto para os aspectos econômicos como ambientais (PAIXÃO et al., 2006). Para Watzlawick et al. (2011), o conhecimento dos teores de carbono em florestas é importante para a quantificação e o planejamento de atividades ligadas à fixação de carbono. Desse modo, pode-se inferir sobre a capacidade de determinado fragmento florestal em contribuir para mitigar a emissão de gases de efeito estufa no seu entorno.

O teor médio de carbono foi significativamente maior na classe miscelânea $(44,46 \%)$ em relação às outras classes de serapilheira (Tabela 2). Raízes, estruturas reprodutivas, galhos e cascas aparecem na sequência, sendo que o menor valor apresentado foi nas folhas. Essa diferença no teor de carbono entre as classes pode ter relação com a taxa de decomposição apresentada pelos diferentes órgãos vegetativos e reprodutivos das plantas. Freschet et al. (2011), quantificou o teor de carbono existente na serapilheira de uma estação experimental da Suécia e após dois anos de incubação deste material realizou nova medição para calcular a variação. Dentre os resultados encontrados, os autores afirmaram que o teor de carbono pode ser utilizado como importante mecanismo para predizer o potencial de decomposição da serapilheira, sendo ainda mais significativo quando se trata de tecidos altamente lignificados. Assim, como as folhas se decompõem geralmente mais rápido que os galhos (ZUO et al., 2018) o menor teor de carbono encontrado para este componente pode ser justificado.

A quantidade de carbono foi significativamente superior na classe galhos e casca (2,76 t/ha). Assim como o aporte de serapilheira, a quantidade e teor de carbono podem variar nas suas diferentes classes. Watzlawick et al. (2011) encontraram no mesmo tipo de floresta, maior concentração de carbono nas folhas $(42,30 \%)$.

O conhecimento sobre o grau de conservação do fragmento florestal urbano avaliado pode subsidiar o planejamento destas áreas no uso público (como parte integrante dos parques urbanos), principalmente no impedimento ao acesso de pessoas no seu interior e na implantação de tratamento paisagístico com espécies ornamentais exóticas no sub-bosque que podem danificar a serapilheira do piso florestal que mostrou ser uma fonte de carbono, além de impactar a biodiversidade local. A retirada da serapilheira em parques urbanos é uma prática comum em algumas cidades, como verificado por Barbosa (2019) em alguns parques urbanos de São Paulo, onde o manejo da serapilheira se realiza por questões estéticas ou de acessibilidade em suas vias. Isto demonstra o desconhecimento do papel da serapilheira na conservação dos fragmentos florestais urbanos.

\section{CONCLUSÕES}

O fragmento florestal avaliado apresentou tanto aporte de serapilheira quanto quantidade e teor de 
carbono semelhantes aos encontrados em florestas com menos intervenções urbanas, demonstrando ser a serapilheira um parâmetro eficiente para se avaliar o estado de conservação destes ambientes. Devido a sua importância no meio urbano, principalmente pelos serviços ecossistêmicos que pode oferecer, recomendase que os gestores municipais disseminem por meio de atividades de educação ambiental, a importância da preservação da serapilheira no piso florestal dos fragmentos existentes nas cidades. Recomenda-se a realização de pesquisas mais aprofundadas neste tema, considerando uma análise temporal mais ampla, para o conhecimento sobre a dinâmica da serapilheira neste e em outros fragmentos florestais urbanos.

\section{REFERÊNCIAS}

AMARAL, R.; COSTA, S. A. P.; MUZZI, M. R. S.. O sequestro de carbono em trechos da floresta urbana de Belo Horizonte: por um sistema de espaços livres mais eficiente no provimento de serviços ecossistêmicos urbanos. Paisagem e Ambiente: Ensaios, São Paulo, n.39, p.163-179, 2017. DOI: https://doi.org/10.11606/issn.2359-5361.v0i39p163$\underline{179}$

BARBOSA, P. O.. Fluxo de carbono via serapilheira em florestas urbanas da cidade de São Paulo: compreensão do funcionamento da infraestrutura verde da cidade. Dissertação (Mestrado em Cidades sustentáveis) Universidade Nove de Julho, São Paulo, 2019.

BERG, B.. Decomposition patterns for foliar litter: A theory for influencing factors. Soil Biology \& Biochemistry Journal, Hoboken, v.78, p.222-232, 2014. DOI: https://doi.org/10.1016/j.soilbio.2014.08.005

BRADFORD, M. A.; BERG, B.; MAYNARD, D. S.; WIEDER, W. R.; WOOD, S. A.. Understanding the dominant controls on litter decomposition. Journal of Ecology, Nottingham, v.104, n.1, p.229-238, 2016. DOI: https://doi.org/10.1111/13652745.12507

CALDEIRA, M. V. W.; VITORINO, M. D.; SCHAADT, S. S.; MORAES, E.; BALBINOT, R.. Quantificação de serapilheira e de nutrientes em uma Floresta Ombrófila Densa. Semina: Ciências Agrárias, Londrina, v.29, n.1, p.53-68, 2008. DOI: http://dx.doi.org/10.1590/S0104-77602014000100002

DICKOW, K. M. C.; MARQUES, R.; PINTO, C. B.; HÖFER, H. Produção de serapilheira em diferentes fases sucessionais de uma floresta subtropical secundária, em Antonina, PR. Cerne, Lavras, v.18, n.1, p.75-86, 2012. Dol: http://dx.doi.org/10.1590/S0104-77602012000100010

ELIAS, G. A.; MARTINS, H. B.; VINHOLES, A. R.; MARQUES, B. H.; CITADINI-ZANETTE, V.; SANTOS, R.. Árvores de um fragmento florestal urbano em Santa Catarina, sul do Brasil: florística e estrutura. Ciência Florestal, Santa Maria, v.28, n.4, p.1755-1769, 2018. DOI: http://dx.doi.org/10.5902/1980509835335

ELMQVIST, T.; SETÄLÄ, H.; HANDEL, S. N.; VAN DER PLOEG, S. ARONSON, J.; BLIGNAUT, J. N.; GÓMEZ-BAGGETHUN, E.; NOWAK, D. J.; KRONENBERG, J.; GROOT, R.. Benefits of restoring ecosystem services in urban areas. Environmental Sustainability, New York, v.14, p.101-108, 2015. DOI: https://doi.org/10.1016/j.cosust.2015.05.001
FEARNSIDE, P. M.. Serviços ambientais provenientes de florestas intactas, degradadas e secundárias na Amazônia brasileira. In: PERES, C. A.; GARDNER, T. A.; BARLOW, J.; VIEIRA, I. C. G.. Conservação da Biodiversidade em Paisagens Antropizadas do Brasil. Curitiba: Universidade Federal do Paraná, 2013. p.26-57.

FIGUEIREDO FILHO, A.; MORAES, G. F.; SCHAAF, L. B.; FIGUEIREDO, D. J. Avaliação estacional da deposição de serapilheira em uma Floresta Ombrófila Mista localizada no sul do estado do Paraná. Ciência Florestal, Santa Maria, v.13, n.1, p.11-18, 2003.

DOI: http://dx.doi.org/10.5902/198050981718

FlOSS, P. A.; CALDATO, S. L.; BOHNER, J. A. M.. Producão e decomposicão de serapilheira na Floresta Ombrofila Mista da Reserva Florestal da Epagri/Embrapa de Caçador, SC. Agropecuária Catarinense, Florianópolis, v.12, n.2, p.19-22, 1999.

FRESCHET, G. T.; AERTS, R.; CORNELISSEN, J. H. C.. A plant economics spectrum of litter decomposability. Functional Ecology, London, v.26, p.56-65, 2011. DOI: https://doi.org/10.1111/j.1365-2435.2011.01913.x

FRESCHET, G. T.; CORNWELL, W. K.; WARDLE, D. A.; ELUMEEVA, T. G.; LIU, W.; JACKSON, B. G.; ONIPCHENKO, V G.; SOUDZILOVSKAIA, N. A.; TAO, J.; CORNELISSEN, J. H. Linking litter decomposition of above-and below-ground organs to plant-soil feedbacks worldwide. Journal of Ecology, London, v.101, n.4, p.943-952, 2013. DOI: https://doi.org/10.1111/1365-2745.12092

GODINHO, T. O.; CALDEIRA, M. V. W.; CALIMAN, J. P.; PREZOTTI, L. C.; WATZLAWICK, L. F.; AZEVEDO, H. C. A.; ROCHA, J. H. T.. Biomassa, macronutrientes e carbono orgânico na serapilheira depositada em trecho de Floresta Estacional Semidecidual Submontana, ES. Scientia Forestalis, Piracicaba, v.41, n.97, p.131-144, 2013. DOI: https://doi.org/10.1590/S0104-77602014000100002

GODINHO, T. D. O.; CALDEIRA, M. V. W.; ROCHA, J. H. T.; CALIMAN, J. P.; TRAZZI, P. A.. Quantificação de biomassa e nutrientes na serapilheira acumulada em trecho de Floresta Estacional Semidecidual Submontana, ES. Cerne, Lavras, v.20, n.1, p.11-20, 2014. DOI: https://doi.org/10.1590/S0104-77602014000100002

IPPUC. Instituto de Pesquisa e Planejamento Urbano de Curitiba. Nossa Curitiba: perfil físico: territorial e socioeconômico da cidade de Curitiba, 2015. Curitiba: IPPUC, 
2015.

LLAUSÀS, A.; NOGUÉ, J.. Indicators of landscape fragmentation: the case for combining ecological índices and the perceptive approach. Ecological Indicators, Coimbra, v.15, n.1, p.85-91, 2012.

MAAS, G. C. B.. Compartimentação do estoque de carbono em Floresta Ombrófila Mista. Tese (Doutorado em Engenharia Florestal) - Universidade Federal do Paraná, Curitiba, 2015.

MACHADO, S. A.; NASCIMENTO, R. G. M.; AUGUSTYNCZIK, A. L. D.; SILVA, L. C. R.; FIGURA, M. A.; PEREIRA, E. M.; TÉO; S. J.. Comportamento da relação hipsométrica de Araucaria angustifolia no capão da Engenharia Florestal da UFPR. Pesquisa Florestal Brasileira, Colombo, n.56, p.5-16, 2008.

MACHADO, M. R.; PIÑA-RODRIGUES, F. C. M.; PEREIRA, M. G.. Produção de serrapilheira como indicador de recuperação em plantio adensado de revegetação. Revista Árvore, Viçosa, v.32, n.1, p.143-151, 2008. DOI: https://doi.org/10.1590/S0100-67622008000100016

MEXIA, T.; VIEIRA, J.; PRÍNCIPE, A.; ANJOS, A.; SILVA, P.; LOPES, N.; FREITAS, C.; SANTOS-REIS, M.; CORREIA, O.; BRANQUINHO, C.; PINHO, P.. Ecosystem services: Urban parks under a magnifying glass. Environmental Research, New York, v.160, p.469-478, 2018. DOI: https://doi.org/10.1016/i.envres.2017.10.023

MUÑOZ, A. M. M.; FREITAS, S. R.. Importância dos serviços ecossistêmicos nas cidades: revisão das publicações de 2003 a 2015. Revista de Gestão Ambiental e Sustentabilidade, São Paulo, v.6, n.2, p.89-104, 2017.

NOWAK, D. J.; CRANE, D. E.. Carbon storage and sequestration by urban trees in the USA. Environmental Pollution, Amsterdam, v.116, p.381-389, 2002. DOI: https://doi.org/10.1016/S0269-7491(01)00214-7

O'CONNELL, A. M.; SANKARAN, K. V.. Organic matter accretion, decomposition and mineralisation. In: NAMBIAR, E. K. S.; BROWN, A. G.. Management of soil, nutrients and water in tropical plantations forests. Canberra: ACIAR; Melbourne: CSIRO, 1997. p.443-480.

OLIVEIRA, L. P.. Carbono e nutrientes no solo e na serapilheira em Floresta Ombrófila Mista Montana e plantio de Pinus elliottii Engelm. Dissertação (Mestrado em Manejo Sustentável de Recursos Naturais) - Universidade Estadual do Centro-Oeste, Irati, 2010.

PAIXÃO, F. A.; SOARES, C. P. B.; JACOVINE, L. A. G.; SILVA, M. L.; LEITE, H. G.; SILVA, G. F.. Quantificação do estoque de carbono e avaliação econômica de diferentes alternativas de manejo em um plantio de eucalipto. Árvore, Viçosa, v.30, n.3, p.411-420, 2006. DOI: https://doi.org/10.1590/S0100$\underline{67622006000300011}$

RONDON NETO, R. M.; KOZERA, C.; ANDRADE, R. R.; CECY, A. T.; HUMMES, A. P.; FRITZSONS, E.; CALDEIRA, M. V. W.;
MACIEL, M. N. M.; SOUZA, M. K. F.. Caracterização florística e estrutural de um fragmento de floresta ombrófila mista, em Curitiba, PR - Brasil. Floresta, Curitiba, v.32, n.1, p.3-16, 2002. DOI: http://dx.doi.org/10.5380/rf.v32i1.2366

SANQUETTA, C. R.; MAAS, G. C. B.; OLIVEIRA, I. M. DE; SANQUETTA, M. N. I.; CORTE, A. P. D.. Dinâmica sazonal da produção de serapilheira em fragmento de Floresta Ombrófila Mista Montana no estado do Paraná.

Enciclopédia Biosfera, Goiânia, v.13 n.24; p.413-422, 2016.

SCORIZA, R. N; CORREIA, M. E. F.; SILVA, E. M. R.. O estoque de serrapilheira é eficiente como indicador ambiental em fragmentos florestais de encosta? Revista Brasileira de Ciências Agrárias, Recife, v.12, n.1, p.79-85, 2017. DOI: http://doi.org/10.5039/agraria. v12i1a5418

VIDAL, M. M.; PIVELLO, V. R.; MEIRELLES, S. T.; METZGER, J. P.. Produção de serapilheira em floresta Atlântica secundária numa paisagem fragmentada (Ibiúna, SP): importância da borda e tamanho dos fragmentos. Revista Brasileira Botânica, São Paulo, v.30, n.3, 2007. DOI: https://doi.org/10.1590/S0100-84042007000300016

ZUO, J.; HEFTING, M. M; BERG, M.P; LOGTESTIJN, R.S.P.; HAL, J.; GOUDZWAARD, L.; LIU, J. C.; SASS-KLAASSEN, U.; STERCK, F. J. POORTER, L.; CORNELISSEN, J. H. C.. Is there a tree economics spectrum of decomposability?. Soil Biology and Biochemistry, Amsterdam, v.119, p.135-142, 2018. DOI: https://doi.org/10.1016/i.soilbio.2018.01.019

WATZLAWICK, L. F.; EBLING, Â. A.; RODRIGUES, A. L.; VERES, Q. J. I.; LIMA, A. M.. Variação nos teores de carbono orgânico em espécies arbóreas da Floresta Ombrófila Mista. Floresta e Ambiente, Seropédica, v.18, n.3, p.248-258, 2011. DOI: http://dx.doi.org/10.4322/floram.2011.045

WATZLAWICK, L. F.; CALDEIRA, M. V. W; VIERA, M.; SCHUMACHER, M. V.; GODINHO, T. O.; BALBINO, R.. Estoque de biomassa e carbono na Floresta Ombrófila Mista Montana Paraná. Scientia Forestalis, Piracicaba, v.40, n.95, p.353-362, 2012

WATZLAWICK, L. F.; KIRCHNER, F. F.; SANQUETTA, C. R.; SCHUMACHER, M. V.. Fixação de carbono em Floresta Ombrófila Mista em diferentes estágios sucessionais. In: SANQUETTA, C. R.; WATZLAWICK, L. F.; BALBINOT, R. M.; ZILIOTTO, M. A. B.; GOMES, F. S.. As florestas e o carbono. Curitiba: UFPR, 2002. p.153-173.

WISNIEWSKI, C.; RIBAS, M. E.; KRIEGER, A.; CURSIO, G. Produção e decomposição da serapilheira e deposição de nutrientes em um trecho de uma Floresta Ombrófila Mista sobre Latossolo Vermelho-escuro, no segundo planalto Paranaense. In: CONGRESSO BRASILEIRO DE CIÊNCIAS DO SOLO. SOCIEDADE BRASILEIRA DE CIÊNCIAS DO SOLO, 26. Anais. Rio de Janeiro: Sociedade Brasileira de Ciência do Solo, 1997.

WREGE, M. S.; FRITZSONS, E.. Dados climáticos dos municípios da região Sul do Brasil. Colombo: Embrapa Florestas, 2015.

A CBPC - Companhia Brasileira de Produção Científica (CNPJ: 11.221.422/0001-03) detém os direitos materiais desta publicação. Os direitos referem-se à publicação do trabalho em qualquer parte do mundo, incluindo os direitos às renovações, expansões e disseminações da contribuição, bem como outros direitos subsidiários. Todos os trabalhos publicados eletronicamente poderão posteriormente ser publicados em coletâneas impressas sob coordenação da Sustenere Publishing, da Companhia Brasileira de Produção Científica e seus parceiros autorizados. Os (as) autores (as) preservam os direitos autorais, mas não têm permissão para a publicação da contribuição em outro meio, impresso ou digital, em português ou em tradução. 